\title{
A Case of Transient Advanced Atrioventricular Block after Aortic Valve Replacement, Report of a Case*
}

\author{
Wataru Hashimoto ${ }^{1,2 \#}$, Shinichiro Taniguchi ${ }^{2}$, Ryuichiro Shibata $^{2}$, Takashi Miura ${ }^{1}$, \\ Tomohiro Odate $^{1}$, Kazuki Hisatomi ${ }^{1}$, Kiyoyuki Eishi ${ }^{1}$ \\ ${ }^{1}$ Department of Cardiovascular Surgery, Nagasaki University Hospital, Nagasaki, Japan; ${ }^{2}$ Department of Cardiovascular Surgery, \\ Sasebo Cyuo Hospital, Sasebo, Japan. \\ Email: " coolcat_watawata0127@yahoo.co.jp
}

Received November $1^{\text {st }}, 2013$; revised December $1^{\text {st }}, 2013$; accepted December $8^{\text {th }}, 2013$

Copyright (c) 2013 Wataru Hashimoto et al. This is an open access article distributed under the Creative Commons Attribution License, which permits unrestricted use, distribution, and reproduction in any medium, provided the original work is properly cited. In accordance of the Creative Commons Attribution License all Copyrights @ 2013 are reserved for SCIRP and the owner of the intellectual property Wataru Hashimoto et al. All Copyright (C) 2013 are guarded by law and by SCIRP as a guardian.

\begin{abstract}
Approximately $3 \%-11.8 \%$ of cases require permanent pacemaker implantation due to atrioventricular block (AVB) after aortic valve replacement (AVR), and determination of conduction disturbances such as left or right bundle branch block by preoperative electrocardiography is correlated with high risk postoperative permanent pacemaker implantation. Intraoperative risk factors include severe calcification of the aortic valve, prolonged cardiopulmonary bypass time, aortic clamp time. Recently, there have been reports of high rates of pacemaker implantation (14.2\%) after transcatheter aortic valve implantation. The time of permanent pacemaker implantation after AVB is often 4 - 10 days, and the European Society of Cardiology guidelines recommend a period of seven days of persistent atrioventricular block postsurgery prior to permanent pacemaker implantation. We report a 79-year-old woman in which the patient developed high-degree AVB after AVR was performed for severe aortic stenosis with complete right bundle branch block. However, her pulse returned to sinus rhythm 7 days postsurgery.
\end{abstract}

Keywords: Aortic Valve Replacement; Permanent Pacemaker Implantation; Transient High-Degree Atrioventricular Block; Transcatheter Aortic Valve Implantation

\section{Introduction}

Approximately 3\% - 11.8\% (mean, $7.0 \%$ ) of cases require permanent pacemaker implantation (PMI) due to highdegree atrioventricular block (AVB) after aortic valve replacement (AVR), and determination of conduction disturbances such as left or right bundle branch block by preoperative electrocardiography is associated with high postoperative PMI risk [1]. We experienced a case in which the patient developed high-degree AVB after AVR was performed for severe aortic stenosis (AS) with complete right bundle branch block (CRBBB). However, her pulse returned to sinus rhythm 7 days postsurgery.

\section{Case Report}

A 79-year-old woman, who was examined for hyperten-

"Conflict of interest: The authors do not have any conflict of interest, financial or otherwise, to declare.

"Corresponding author. sion, and AS was diagnosed in 2006. Palpitations were noticed on occasion 2 - 3 years previously and electrocardiographic abnormalities had been indicated. Electrocardiogram findings showed sinus rhythm, a heart rate of 70 bpm, left axis deviation, and CRBBB (Figure 1). The patient treated heart failure in July 2011. Blood pressure was 106/60 mmHg, and a Levine III/IV systolic murmur was detected in the 2RSB. Laboratory dates were within normal levels. The chest radiographic imaging showed a cardiothoracic ratio of 53\%. Cardiac echocardiography revealed left ventricular end-diastolic dimension/endsystolic dimension; 53/32 mm, left ventricular ejection fraction; 70\%, maximum aortic valve pressure gradient/ mean gradient; 96/52 mmHg, aortic valve area; $0.89 \mathrm{~cm}^{2}$ and mild aortic regurgitation. Cardiac catheterization showed left ventricular aortic pull-back pressure; 66 mmHg, aortic regurgitation $2^{\circ}$, and no significant stenosis in the coronary artery. We diagnosed severe AS and 


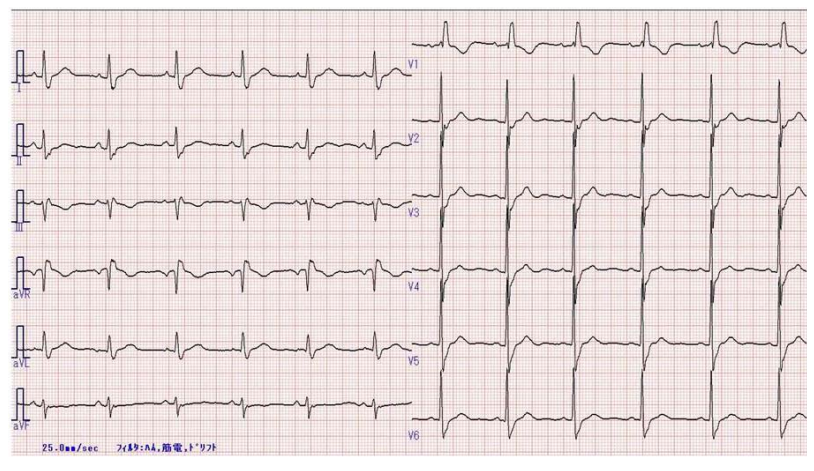

Figure 1. Preoperative electrocardiogram. Confirmed left axis deviation and complete right bundle branch block. PR interval, 0.156 s, QRS width, $0.150 \mathrm{~s}$.

performed AVR. The operation was performed via the median sternotomy. After cardiac arrest, we chose a 19 mm Carpentier-Edwards PERIMOUNT MAGNA EASE TFX and we transplanted the biological valve to the intra-annular region using an everting mattress suture technique. The total surgical time was prolonged by $189 \mathrm{~min}$ for the cardiopulmonary bypass time and 154 min for the aortic clamp time. Because the patient was an elderly woman with calcification in the annuloaortic area and bleeding from the incision line at the ascending aorta. After the surgery peak creatine kinase (CK), peak aspartate aminotransferase (AST), and lactate dehydrogenase (LDH) levels were $1781 \mathrm{IU} / \mathrm{L}, 60 \mathrm{IU} / \mathrm{L}$, and $463 \mathrm{IU} / \mathrm{L}$, respectively. Her own beat was not detected after the aortic clamp off, indicating high-degree AVB; therefore, the patient was weaned off the cardiopulmonary bypass using temporary ventricular pacing. On electrocardiography, we confirmed a P-wave rate of $75 /$ min post-operatively but no following QRS wave was noted (Figure 2). She was weaned off the respirator 12 hours post-operatively. However, there was still no evidence of the QRS wave after the P wave, so we applied transvenous temporary ventricular pacing. We also considered a permanent pacemaker and managed her condition, finally her pulse returned to sinus rhythm on day 7 postoperatively, and she was then discharged from the hospital.

\section{Discussion}

Reports suggest that approximately $3 \%-11.8 \%$ (mean, 7.0\%) cases require a PMI due to high-degree AVB after AVR [1]. Damage or functional pressurization of the conduction system, which consists of the subcommissural region between the right and left coronary cusps, causes AVB. Matthews [1] analyzed 7 reports [2-6] of the relationship between AVR and permanent PMI and reported that confirmation of right or left bundle blocks and 1-degree AVB on preoperative electrocardiography are risk factors for postoperative PMI. Erdogan et al. [2] and Elahi et al. [3] reported that other risk factors in-

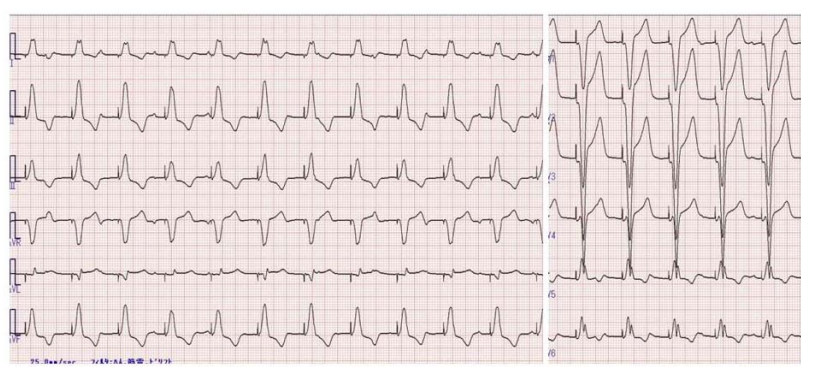

Figure 2. Postoperative electrocardiogram. Ventricular pacing rhythm and $P$ wave was confirmed at $73 / \mathrm{min}$, but no QRS was detected following $P$ wave.

cluded aortic valve calcification and bicuspid valve, as well as perioperative factors, including prolonged duration on cardiopulmonary bypass time and aortic clamp time. Operative procedures can affect the conduction system during removal of calcification in highly calcified annular in AS. On the other hand, Limongelli et al. [4] and Dawkins et al. [5] reported that aortic regurgitation (AR) is a risk factor, and it remains unclear whether AS or AR is more likely to occur after postoperative AVB. Bagur et al. [7] conducted a prospective study of 780 AS cases that underwent AVR and found that the prevalence of early PMI after AVR was 3.2\%, with risk factors such as left bundle block (odds ratio [OR], 4.65) and right bundle block (OR, 4.21). Although PMI increases the hospitalization duration, they reported no difference in mortality rate or 5-year survival. Totaro et al. [6] reported that a continuous suture technique is more likely to cause AVB compared to the interrupted suture technique.

If we examine the data described above, this patient was confirmed preoperatively for left axis deviation and CRBBB, as well as a high possibility of left branch bundle block, which confers a high risk of postoperative AVB. Intraoperative risk factors included calcification of the annular, prolonged duration on the cardiopulmonary bypass time and aortic clamp time may be relevant to postoperative AVB. We inferred that the pulse recovery was due to recovery of the His bundle or disappearance of the myocardial edema.

Recently, transcatheter aortic valve implantation (TAVI) has been used to manage AS; however, the analysis of Bates et al. [8] of 14 studies on post-TAVI PMI suggested that the rate of PMI after TAVI was high at $14.2 \%$. Compared to $5.4 \%$ for the Edwards Sapien valve (Edwards Lifesciences Inc, Irvine, CA) group, the rate was $20.8 \%$ for the CoreValve (CoreValve Inc, Irvine, CA) group, indicating a significantly higher rate. Jilaihawi et al. [9] suggest that there was increased stress to the left branch of the His bundle because the stent region of the CoreValve is long and self-extending.

Although our patient's pulse returned to sinus rhythm 7 days after the surgery, a 4 - 10 day window after AVB 
is most common for PMI[1], and the European Society of Cardiology recommends permanent PMI if complete AVB continues for 7 days after surgery[10].

\section{Conclusion}

We performed AVR for a severe AS with CRBBB and experienced the onset of temporary but severe postoperative high-degree AVB. We also reported that permanent PMI as a common complication of both AVR and TAVI.

\section{REFERENCES}

[1] I. G. Matthews, I. A. Fazal, M. G. Bates and A. J. Turley, "In Patients Undergoing Aortic Valve Replacement, What Factors Predict the Requirement for Permanent Pacemaker Implantation?” Interactive CardioVasc Thoracic Surgery, Vol. 12, No. 3, 2011, pp. 475-479. http://dx.doi.org/10.1510/icvts.2010.254607

[2] H. B. Erdogan, N. Kayalar, H. Ardal, S. N. Omeroglu, K. Kirali, M. Guler, et al., "Risk Factors for Requirement of Pacemaker Implantation after Aortic Valve Replacement,” Journal of Cardiac Surgery, Vol. 21, No. 3, 2006, pp. 211-215. http://dx.doi.org/10.1111/j.1540-8191.2006.00216.x

[3] M. Elahi and K. Usmaan, "The Bioprosthesis Type and Size Influence the Postoperative Incidence of Permanent Pacemaker Implantation in Patients Undergoing Aortic Valve Surgery,” Journal of Interventional Cardiac Electrophysiology, Vol. 15, No. 2, 2006, pp. 113-118. http://dx.doi.org/10.1007/s10840-006-7750-4

[4] G. Limongelli, V. Ducceschi, A. D’Andrea, A. Renzulli, B. Sarubbi, M. De Feo, et al., "Risk Factors for Pacemaker Implantation Following Aortic Valve Replacement: A Single Center Experience,” Heart, Vol. 89, No. 8, 2003, pp. 901-904. http://dx.doi.org/10.1136/heart.89.8.901

[5] S. Dawkins, A. Hobson, P. Kalra, A. T. Tang, J. L.
Monro and K. D. Dawkins, "Permanent Pacemaker Implantation after Isolated Aortic Valve Replacement,” The Annals of Thoracic Surgery, Vol. 85, No. 1, 2008, pp. 108-112.

http://dx.doi.org/10.1016/j.athoracsur.2007.08.024

[6] P. Totaro, G. Calamai, G. Montesi, C. Barzaghi and M. Vaccari, "Continuous Suture Technique and Impairment of Atrioventricular Conduction after Aortic Valve Replacement," Journal of Cardiac Surgery, Vol. 15, No. 6, 2000, pp. 418-422. http://dx.doi.org/10.1111/j.1540-8191.2000.tb01302.x

[7] R. Bagur, J. M. Manazzoni, E. Dumont, D. Doyle, J. Perron, F. Dagenais, et al., "Permanent Pacemaker Implantation Following Isolated Aortic Valve Replacement in Large Cohort of Elderly Patients with Severe Aortic Stenosis,” Heart, Vol. 97, No. 20, 2011, pp. 1687-1694. http://dx.doi.org/10.1136/heartjnl-2011-300308

[8] M. G. Bates, I. G. Matthews, I. A. Fazal and A. J. Turley, "Postoperative Permanent Pacemaker Implantation in $\mathrm{Pa}$ tients Undergoing Trans-Catheter Aortic Valve Implantation: What Is the Incidence and Are There Any Predicting Factors?” Interactive CardioVasc Thoracic Surgery, Vol. 12, No. 2, 2011, pp. 243-253. http://dx.doi.org/10.1510/icvts.2010.256578

[9] H. Jilaihawi, D. Chin, M. Vasa-Nicotera, M. Jeilan, T. Spyt, G. A. Ng, et al., "Predictors for Permanent Pacemaker Requirement after Transcatheter Aortic Valve Implantation with the Core Valve Bioprosthesis," American Heart Journal, Vol. 157, No. 5, 2009, pp. 860-866. http://dx.doi.org/10.1016/j.ahj.2009.02.016

[10] P. E. Vardas, A. Auricchio, J. J. Blanc, J. C. Daubert, H. Drexler, H. Ector, et al., "Guidelines for Cardiac Pacing and Cardiac Resynchronization Therapy. The Task Force for Cardiac Pacing and Cardiac Resynchronization Therapy of the European Society of Cardiology. Developed in Collaboration with the European Heart Rhythm Association,” European Heart Journal, Vol. 28, No. 18, 2007, pp. 2256-2295. http://dx.doi.org/10.1093/eurheartj/ehm305 